\title{
LA ESQUIZOFRENIA Y SU SEXUALIDAD
}

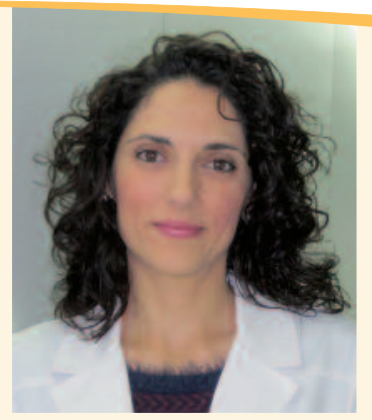

\section{BERTA CEJAS PASCUAL}

Psiquiatra. Coordinadora de la Unidad de Esquizofrenia y Otros Trastornos Psicóticos, Trastornos Bipolares y Adicciones a Sustancias. Hospital Universitari Dexeus. Barcelona.

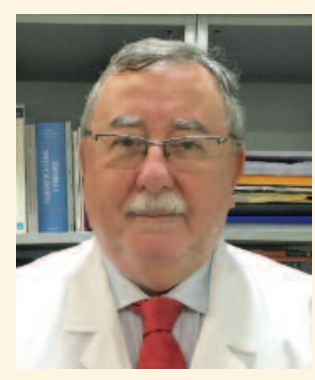

\section{JOSEP MARIA FARRÉ MARTÍ}

Psiquiatra. Jefe de servicio. Servicio de Psiquiatría, Psicología y Medicina Psicosomática. Hospital Universitari Dexeus. Barcelona.

\section{INTRODUCCIÓN}

La sexualidad es un acto fisiológico que permite la perpetuación de la especie humana y, además, produce placer en el ser. Siendo así, no es difícil de entender que todo ser humano deba tener una vida sexual plena o lo más plena dentro de sus posibilidades. No obstante, en los pacientes con esquizofrenia, se ha priorizado el trastorno de base y su conducta sexual ha sido desestimada e infravalorada, considerando que no es importante por el mero hecho de padecer un trastorno mental, excluyéndose de la entrevista clínica por pensar que el paciente no tiene interés por ella y por la propia incomodidad del clínico al interrogar sobre ella. Este gran error se ha de subsanar, pues se ha demostrado que las alteraciones en el área sexual repercuten negativamente en la evolución de la patología psiquiátrica, disminuyendo la autoestima y dificultando las relaciones.

Correspondencia: Berta Cejas Pascual Correo electrónico: bertacejas@hotmail.com

\section{PREVALENCIA Y} PECULIARIDADES DE LA ACTIVIDAD SEXUAL EN EL PACIENTE CON ESQUIZOFRENIA

Varios autores evidencian que un gran porcentaje de pacientes del ámbito ambulatorio e intrahospitalario han sido y son activos sexualmente. Esta actividad pasa tanto por relaciones heterosexuales y homosexuales (con parejas estables o no) como por masturbaciones. Sin embargo, no todos tendrían una actividad sexual satisfactoria1-3.

Por otro lado, debido a las características propias de la enfermedad, presentan determinadas peculiaridades que, aunque no son exclusivas de ellos, por su gran impacto, requieren mención específica:

- Probabilidad de experimentar abuso sexual: varios estudios avalan una mayor prevalencia de abuso sexual en comparación con la población sana. 
- Conductas sexuales mal adaptadas: la enfermedad puede interferir en el desarrollo y maduración, interrumpiendo o dificultando la adquisición de las habilidades interpersonales, obstaculizando, así, la exploración sexual saludable, lo cual se traduce posteriormente en una mala expresión del sexo.

- Mayor riesgo de contraer el virus de la inmunodeficiencia humana (VIH) debido a: mayor promiscuidad, experiencias homosexuales, prostitución, bajo uso del preservativo, comorbilidad con trastornos por abuso de sustancias, conductas impulsivas, etcétera4 ${ }^{4}$.

- Disfunción sexual: puede afectar a cualquier etapa del acto sexual (deseo, excitación y orgasmo), y puede ser debida a varios factores ${ }^{5-7}$ :

1. La propia sintomatología positiva y negativa de la esquizofrenia.

2. La comorbilidad con otros trastornos psiquiátricos: afectivos, de ansiedad, de personalidad o por abuso de sustancias.

3. Altas tasas de hipertensión arterial, diabetes mellitus, hipercolesterolemia, enfermedad cardíaca y obesidad acompañan a nuestros pa cientes. Se deben, en parte, a los malos hábitos higiénico-dietéticos y al sedentarismo y, por otro lado, al síndro-

\section{Las disfunciones sexuales tienen un impacto importante y negativo en la calidad de vida; de hecho, muchos pacientes las consideran más molestas que cualquier síntoma psicótico}

me metabólico propio de los antipsicóticos.

4. Tratamiento antipsicótico: los antipsicóticos o neurolépticos afectan a la excitación, el orgasmo y la satisfacción sexual, además de producir amenorrea, galactorrea, ginecomastia y, en ocasiones, priapismo. Todos ellos son reversibles con el cese del tratamiento, excepto el priapismo, que, en ocasiones, requiere intervención quirúrgica. El mayor problema derivado de la disfunción sexual secundaria al tratamiento es el incumplimiento terapéutico, con las consecuentes recaídas y aumento del deterioro de los pacientes tanto a nivel psíquico como físico y social. Así pues, será importante tener en cuenta este aspecto a la hora de seleccionar el tratamiento farmacológico. A nivel clínico, se han establecido tres mecanismos por los cuales se produce esta disfunción:

- Bloqueo directo de los receptores $D_{2}$ de dopamina (este neurotransmisor es el responsable de la motivación, el deseo y la excitación).

- Aumento de prolactina (que bloquea la dopamina).

- Antagonismo en los receptores adrenérgicos $\alpha_{1}$ (causante de disfunción).

\section{SEXUALIDAD Y CALIDAD DE VIDA EN LA ESQUIZOFRENIA}

La calidad de vida de todo ser humano pasa por tener un bienestar físico, psíquico, social y, cómo no, sexual. Si analizamos estos cuatro puntos, observamos que la calidad de vida de los pacientes con esquizofrenia se puede ver truncada por afectación de cualquiera de los cuatro o de todos ellos (muchos están interrelacionados $y$, al modificar uno, mejoramos otro también). Si las analizamos, observamos que las disfunciones sexuales tienen un impacto importante y negativo en la calidad de vida; de hecho, muchos pacientes las consideran más molestas que cualquier síntoma psicótico. Así pues, la sexualidad es un tema que abordar junto al paciente y su pareja si la tiene para poder establecer estrategias 
preventivas o correctivas de cualquier alteración.

\section{ESTRATEGIAS \\ PREVENTIVAS EN LA DISFUNCIÓN SEXUAL EN LA ESQUIZOFRENIA}

Lo más importante es realizar una entrevista clínica en la cual podamos hablar abiertamente de la sexualidad. Se preguntará sobre la existencia o no de actividad sexual y el tipo, si es satisfactoria o no y por la presencia o ausencia de disfunción sexual. En caso de que existan alteraciones, se indagará para ver la raíz de estas y el momento en que aparecen: si antes de la enfermedad, con esta o con el tratamiento. Existen una serie de escalas y cuestionarios que nos pueden ayudar en esta tarea8: la Escala de calidad de vida, los Cuestionarios de cambios en la función sexual, la Escala de experiencia sexual de Arizona o el Cuestionario de disfunción sexual secundaria a psicofármacos. Con toda esta información, se podrá trazar un plan de trabajo para paliar las adversidades y, en función del estadio en el que estemos, hablaremos de prevención primaria o secundaria:
1. Prevención primaria: es la realizada cuando el paciente niega disfunción sexual y consistirá en técnicas para evitar su aparición:

- Potenciar hábitos higiénicodietéticos.

- Evitar el sedentarismo.

- Tratar las enfermedades metabólicas concomitantes.

- Indicar la abstinencia de tóxicos.

- Tratar la sintomatología positiva y negativa.

- Realizar terapia sexual individual o de pareja.

2. Prevención secundaria: se utiliza cuando la disfunción sexual ya está instaurada y su objetivo será disminuirla o eliminarla. Las medidas son las citadas en la prevención primaria junto a estas:

- Esperar a la remisión espontánea, con baja tasa de éxitos.

- Reducir la dosis de antipsicótico, de forma progresiva y vigilando la aparición de recaídas.

- Cambiar por otro antipsicótico con bloqueo reducido de los receptores $D_{2}$, menor aumento de prolactina y

\section{La disfunción sexual secundaria a}

los psicofármacos es causante del incumplimiento terapéutico, con sus consecuentes recaídas, deterioro físico, social y mental

\section{CONCLUSIONES}

Pese a lo que se podría creer en un principio, se ha comprobado que una gran proporción de pacientes con esquizofrenia son sexualmente activos, aunque solo un tercio de ellos presente una sexualidad satisfactoria. La insatisfacción sexual y su disfunción son generadoras de un empeoramiento en la calidad de vida, con lo cual, es importante que dediquemos un tiempo de la entrevista clínica a explorarlas, teniendo en cuenta las particularidades que estos pacientes pueden presentar. Una vez analizado el problema, podremos aplicar la estrategia preventiva que mejor se adapte a cada paciente. Por otro lado, se debe resaltar que la disfunción 
sexual secundaria a los psicofármacos es causante del incumplimiento terapéutico, con sus consecuentes recaídas, deterioro físico, social y mental, con lo cual, es necesario que el médico conozca la función sexual antes y después del tratamiento y consensuar con el paciente la opción terapéutica que mejore tanto su psicopatología como su calidad de vida.

\section{BIBLIOGRAFÍA}

1. Díaz-Morfa J. El paciente esquizofrénico y su sexualidad: conductas y trastornos sexuales. Psiq Biol. 2006;13(1):22-9.

2. Jacobs P, Bobek SC. Sexual needs of the schizophrenic client. Pers- pect Psychiatr Care. 1991;27(1) 15-20.

3. Welch SJ, Clements GW. Development of a policy on sexuality for hospitalized chronic psychiatric patients. Can J Psychiatry. 1996; 41(5):273-9.

4. Kalichman SC, Kelly JA, Johnson JR, Bulto M. Factors associated with risk for HIV infections among chronic mentally ill adults. Am J Psychiatry. 1994;151(2):221-7.

5. Montejo González AL, Grupo Español de Trabajo para el Estudio de las Disfunciones Sexuales Secundarias a Psicofármacos. Disfunción sexual provocada por antipsicóticos. Impacto clínico y propuestas de actuación. En: Montejo González AL (coord.). Sexualidad y salud mental. Barcelona: Editorial Glosa, S.L.; 2003. p. 15-36.
6. Martín Navarro N, Vega Fernández FM, Montejo González AL. Sexualidad en la esquizofrenia. En: Montejo González AL (coord.). Sexualidad y salud mental. Barcelona: Editorial Glosa, S.L.; 2003. p. 117-28.

7. Nestoros JN, Lehmann HE, Ban TA. Sexual behavior of the male schizophrenic: the impact of illness and medications. Arch Sex Behav. 1981;10(5):421-42.

8. García-Portilla González MP, Bascarán Fernández MT, Sáiz Martínez PA, Parellada Redondo $\mathrm{M}$, Bousoño García M, Bobes García J. En: García-Portilla González MP, Bascarán Fernández MT, Sáiz Martínez PA, Parellada Redondo M, Bousoño García M, Bobes García J. Banco de instrumentos básicos para la práctica de la psiquiatría clínica. 7. ${ }^{a}$ ed. Majadahonda: CYESAN; 2015. p. 167-280. 